\title{
Research on the Intellectual Property Right in the Information Resources Sharing of Digital Library
}

\author{
Minghui Su \\ Baicheng Normal University, Baicheng, Jilin, 137000, China \\ email: bcsmh@163.com
}

Keywords: digital library; intellectual property rights; information resource; risk; measures

\begin{abstract}
The rapid development of information technology and computer network has played an important role in improving the service function of modern library and has created favorable conditions for the rapid development of digital library. Compared with the general library, digital library has obvious advantages in the aspects of resource sharing, intelligence level, resource integration and so on, and can meet the user's multiply needs. Combined with the actual development of the digital library, we can see that the digital library has the problem of intellectual property rights in the sharing of all kinds of books, which has a negative impact on the legitimate rights and interests of the right holder, and increases the probability of the occurrence of various rights events. In order to change the adverse current situation of the development, we need to combine the characteristics of the digital library and the information resources sharing mechanism, analyze in-depth the problems of intellectual property rights, and take the necessary measures to coordinate the three interests among the library, the user and the oblige to realize the effective avoidance of intellectual property risk in library information resource sharing, promoting the rapid development of China's digital library. Based on the above, the problem of intellectual property rights in the sharing of information resources of digital library is studied deeply in this paper.
\end{abstract}

\section{Introduction}

The emergence of digital library and the expansion of its practical application range provide a great convenience for users to search all kinds of information, achieve the sharing of various types of books, and improve the efficiency of the use of library resources. However, with realizing the goal of sharing information resources of digital library, the intellectual property issues has damaged the legitimate rights and interests of all kinds of resource owners, which bring some hidden dangers in the information resources sharing of digital library. Therefore, the necessary research is needed to focus on the issue of intellectual property rights in digital library information resources sharing, and we need strengthen the in-depth analysis of these issues using the reliable analysis method, so as to provide the reliable guarantee for formulating and implementation the related measures, and establish a good relationship among users, library, and the rights to the actual needs, promoting the steady development of digital the library in our country [1].

\section{The Main Functions of Digital Library and the Necessity of Strengthening the Intellectual Property Protection of Information Resources}

Pay Attention to the Main Functions of the Library. With the support of reliable computer network and information technology, the overall service level of digital library is increasing constantly, and its structure has been optimized, and the main function of digital library is to provide information services. Paying attention to the construction of information resources of digital library is mainly in order to meet the users multi-level needs, promote the long-term development of digital library for providing good service to customers, and improve its service function and ensure all kinds of information resources to get the maximum use. With the development of digital library, the lack of adequate attention to the information resources services and strengthening the construction of information resources will tend to reduce the service level of 
digital library, and make it difficult to form the characteristics of information resources. Therefore, improving the information service system in digital library and maintaining a good level of service, need to develop in line with their actual situation of service principle and related management mechanism, carry out necessary investigation activities of user demand to promote the construction of information resources and Enhancing the potential value of digital library.

Strengthen the Intellectual Property Protection of Information Resources. If we want to realize the effective construction of the digital library and the sharing of library information resources, and highlight the personalized service of library, it is necessary for mining, sorting and processing in numerous network information resources, and establishing the reliable knowledge service platform, strengthening intellectual property rights protection of legitimate rights and interests of the digital library, which will enable the future digital library to be in a stable and efficient development state for a long time and This will provide a good service for the knowledge demanders [2]. The necessity of strengthening the protection of intellectual property rights in the sharing of information resources in digital libraries specific performances: ensuring that the legitimate rights and interests of the owner of intellectual property rights are not infringed, and maintaining their good enthusiasm for creation, so that the digital library can have more knowledge; in order to make the long-term development of digital library be more standardized, and gradually form a sound knowledge service system, the establishing the relations compliance with the interests of the user, the right person, the library to maintain the stability of the development of the library; strengthening the crackdown on IPR infringement to ensure the full play of the actual role of copyright law and copyright law, and reducing the incidence of intellectual property issues in the sharing of information resources in digital libraries.

\section{The Effective Analysis of All Kinds of Intellectual Property Rights in the Information Resources Sharing of Digital Library}

Copyright Problems in Information Sharing of Digital Library. Through the analysis of different types of digital library, we can know that it is divided into the traditional public library and nontraditional library. There are some differences in the related management mechanism and information resource sharing between different types of library, so it is necessary to analyze the copyright issues of both information resources sharing, specifically in the following aspects:

Copyright problems exist in the sharing of information resources in traditional public libraries [3]. For example, the university library and public library and so on belong to the traditional public library whose information resources sharing includes abundant contents: the database of purchase, the basic digital resources and some characteristics of database. At the same time, many of the works contained in these libraries have been published and published, and formed a wealth of information resources through the role of digital conversion mechanism. In order to protect the intellectual property rights of the traditional public library information resources sharing, the national copyright administration has formulated a series of rules and regulations, which has been necessary for the protection of digital works transformed from the traditional works. Copyright Law clearly points out that the copy of the digital library information resources need to be authorized by the copyright owner, otherwise there will be infringement. At the same time, as an important content of digital library information resources sharing, database development and rational use have relation to the overall service level of the digital library [4]. In the process of selection of various types of data materials, the copyright of the materials should be paid attention, avoiding copying or copying the material content of the information resources of others, and various replication behavior without authorization will increase the risk of copyright, copyright charges in the network dissemination of information resources of digital library in the process of may also occur.

Copyright problems exist in the sharing of information resources in nontraditional public libraries. Such companies are closely related to the development of the Internet, with commercial attributes, such as database development companies and library information resources website. Digital nontraditional companies use a variety of professional and technical means to obtain a copy 
of the database authorized by the author that contain a large number of library resources. If the commercial website without permission of the authors, whose works will be released to the Internet to provide for the user to browse, download and other services, and obtain the relevant income, that will infringing the right of reproduction and the right to network dissemination, increase the copyright problem of digital library information resources sharing in the incidence.

Copyright Problems in Information Resource Sharing of Digital Library. The rapid development of digital technology and the Internet provides great convenience for people to get all kinds of books and information resources, and fully meets the actual needs of the people. As the computer network, mobile phone, TV and so on, they are an important channel for people to obtain information. The digital library is characterized by a wide range of services and no limit of time and space, that has a huge knowledge storage space, allowing users to get the information they need. When disseminating all kinds of books and information and the sharing of library information resources, the digital library must obtain the authorization of the right holder to ensure the legitimacy of library to share all kinds of information resources. If you do not have the right to authorize the free dissemination of books and information resources, that can be regarded as infringement, in the dissemination of information of books to increase the probability of infringement. In the communication of the library information the probability of infringement is increased.

Copyright Problems in the Authorization of Digital Libraries. Combined with the actual situation of all kinds of copyright events in the digital library, it is known that most of these events occur in the digital non-traditional library which is not fully authorized by the author. Because non-traditional digital library under development has its own occurrence mode, information resources sharing is difficult to obtain a complete authorization. When not authorized by the author, school and other aspects, digital library provides users with various types of library information resources, that will arises copyright infringement issues. Therefore, we need to fully consider the integrity of the copyright to avoid the potential infringement problems when the nontraditional digital library sharing all kinds of information resources.

\section{Some Measures to Strengthen the Management of Intellectual Property Rights in the Information Resources Sharing in Digital Libraries}

Perfect Laws and Regulations to Ensure the Balance of Interests of all Parties in the Information Resources Sharing. Any digital libraries are difficult to collect all the library resources and need to combine with other libraries to establish a unified alliance to build a reliable library service platform, achieving the information resources sharing [5]. As the common document delivery, interlibrary mutual, all belong to the information resource sharing of the library alliance. In this model, it is easy to affect the interests of publishers and database providers, leading to the emergence of various types of property disputes. Therefore, it is necessary to perfect a variety of laws and regulations, improve the information service system in digital library to ensure the information resources sharing well, and gradually establish the relationship among stakeholders in intellectual property rights of the information resources sharing to ensure the balance of interests of all parties. To achieve such development goals, we need summarize the main causes of the problems of intellectual property in the digital library information resources sharing, improve the relevant legal system, clear the scope of all kinds of information resources, ensuring intellectual property rights in the resources sharing can be effectively solved. At the same time, the laws and regulations need to confirm the legal license rights of the digital library to guarantee maximum that intellectual property rights is not compromised, realizing the information resources sharing of digital library as well as the probability decrease of the various problems of property disputes.

Pay Attention to the Rational use of Technical Measures and Strengthen the Coordination of the Protection of Intellectual Property Rights in the Information Resources Sharing. In order to adapt to the development requirements of the information era and enhance the overall level of service of digital library, it is necessary to focus on the library information resources sharing that 
can meet the diverse needs of users and improve the utilization efficiency of digital library resources.

Because of the problem of intellectual property right in the information resources sharing of digital library, it affects the long-term stable development of digital library [6]. Therefore, it is necessary to pay attention to the reasonable use of relevant technical measures, and strengthen the coordination of intellectual property rights in the information resources sharing that specific perform in: paying attention to the restriction of non authorized communication and realizing the effective avoidance of intellectual property risk, combined with the digital library information resources sharing mechanism; strengthening the reasonable use of the encryption technology, digital watermarking technology, mobile agent technology and information technology, ensuring the legitimacy of the digital library users to get all kinds of information resources, and realizing the effective protection of the copyright owner of the digital library information resources; strengthening the research and development of various security technologies, enhancing the security of the digital library system, realizing the real-time protection of various information resources to reduce the incidence of intellectual property issues.

Improve the Efficiency of Mining Information Resources Without Intellectual Property Protection and Enrich the Content of Digital Library Resource Sharing. The realization of the goal of sharing information resources of digital library not only meets the needs of users, but also provides a reliable guarantee for the stable development of the library. Therefore, in order to increase the amount of information resources in the digital library, and reduce the incidence of intellectual property rights in the resources sharing, it is necessary to continuously improve the efficiency of mining information resources without intellectual property protection. Like not copyrighted works and all kinds of data, the digital library can take the measures of duplication, resource integration and other measures to realize the deep excavation of information resources to ensure the legitimacy of the sharing of information resources and enrich the content of digital library resource sharing [7]. At the same time, the relevant departments need to actively explore the effective construction of efficient copyright authorization mode to avoid risk effectively in the resources sharing intellectual property to make the user obtain to access all kinds of information resources in the digital library. In addition, the public awareness of IPR protection needs to be constantly strengthened to ensure the stable development of China's knowledge economy society, and enhance the practical effect of the protection of intellectual property rights. The development of digital library in the future also need to pay attention to the development and implementation of a variety of innovative management mechanisms to ensure that information sharing can achieve the desired results to comprehensively improve their overall service level.

\section{Conclusion}

Ensuring the balance of all parties interests of intellectual property in information resources sharing of digital library, affects the pace of the construction of the digital library, which needs the relevant personnel to focus on a comprehensive analysis of the problem and effective treatment. For ensuring that the various resources in the digital library can get the maximum use and maintaining the legitimate rights of users and obliges, it is necessary to increase the legal sanction of all kinds of infringement, which can promote digital library under the development to contain more information resources to meet the actual needs of the people. Therefore, the construction of digital library in the future should pay attention to coordinate the interests of all parties in the process of the information resources sharing to avoid all kinds of intellectual property infringement events, and promote the rapid development of digital library, realize the effective utilization of various types of library information resources, which can lay a solid foundation for the realization of the goal of sharing the information resources of the digital library and the continuous improvement of the overall service level. 


\section{References}

[1]LI Jiangning. Intellectual property risk and its avoidance in the construction and sharing of library information resources [J]. Journal of Longyan Univercity, 2011(05).

[2]HAO Tianxia. Research on intellectual property in the process of digital library information service [J]. Library and Information Service, 2010(07).

[3]CAO Yuping. Research on the strategy of library to avoid intellectual property risk in information resource sharing [J]. Information Science, 2010(09).

[4]WANG Zheng, HONG Weida. Research on copyright in digital library information resources sharing [J]. Information and Documentation Services, 2010(03).

[5]YUAN Jing. Research on risk prevention of library consortia [J]. Journal of Wuhan University, 2010(05).

[6]CHEN Jian. Research on the mode of information resource sharing and copyright of digital library [J], Journal of Heilongjiang University, 2010(06).

[7]LI Hongchang. The problem of intellectual property in the information resource service of digital library [J]. Journal of Liaoning Technical University, 2011(03). 